\title{
Depression and exposure to violence among Venda and Northern Sotho adolescents in South Africa
}

\author{
JM Bach , D Louw \\ Department of Psychology, University of the Free State, Free State, South Africa
}

\begin{abstract}
Objective: Despite the high levels of violence in South Africa, a lacunae in research exists regarding the influence of violence exposure on children. This study investigated the correlation between children's exposure to violence and the development of psychological problems such as depression. Method: 186 Venda and 151 Northern Sotho adolescents were studied in a questionnaire survey to determine this relationship. Two measuring instruments were used: The Children's Depression Inventory and the Child Exposure to Violence Form. Results: When comparing gender, no significant differences were found in terms of overall exposure to violence between males and females. For depression, the total group of girls had a remarkably higher prevalence of depression. Regarding ethnic comparison, no significant differences were found in terms of overall exposure to violence or for witnessed events. However, the Venda adolescents had been victims significantly more often. Venda and Northern Sotho females had a similar prevalence of depression, but Northern Sotho boys had a higher depression rate than Venda boys. The correlation between victimisation and total group depression was relatively low for the Northern Sotho group, and non-existent for the Venda group. A significant correlation was found between total exposure to violence and depression for the overall group. Conclusion: This study indicates that adolescents' exposure to violence and subsequent mental health is an area of concern. However, adolescents could be taught effective coping and problem-solving techniques in schools to help empower them against stressors they might encounter.
\end{abstract}

Key words: Depression; Violence; Adolescents; Venda, Northern Sotho

Received: 10-11-2008

Accepted: 12-02-2009

\section{Introduction}

Children throughout the world are subjected to a multitude of traumatic experiences which vary from natural disasters, accidents and war, to political, community and familial violence. Such exposure can pose a severe threat to a child's well-being.

A child's vulnerability to the damaging effects of stressors is greater than that of adults. ${ }^{1}$ Severe stress triggered by a traumatic event has been related to increased chances of children developing psychological problems such as depression and post-traumatic stress disorder. ${ }^{2,3}$

Although children's exposure to violence have occurred in all societies since the begining of time it is equally true that

\section{Correspondence:}

D Louw

P.O. Box 339, Bloemfontein, 9300, Republic of South Africa

email: louwda.hum@ufs.ac.za there is an increase in the incidence of such traumatic events. ${ }^{4}$ In the United States of America (USA), 85\% of a sample of African American adolescents had been victims of at least one act of interpersonal violence, and 91\% had witnessed a violent event. ${ }^{5}$ In a study among African American and Latino middle school children in a low income neighbourhood in Los Angeles, more than three out of every four children reported high levels of exposure to community violence. ${ }^{6}$ Of this group, $66 \%$ were direct victims. In Finland and Korea $5-10 \%$ of children experience physical violence. Australia figures for domestic violence cases where children were present range from 85- $90 \%$. A study in Nairobi, Kenya, found that $69 \%$ of adolescents had witnessed violence within their communities. ${ }^{8}$

In South Africa it was found that $95 \%$ of the Xhosaspeaking children in the Western Cape had witnessed violence, while $56 \%$ of the children had been victims of violence themselves. ${ }^{9}$ A Cape Town survey found that 62.9\% of the grade 10 adolescents studied had witnessed violence 
in the street, neighbourhood, or school, and $31.6 \%$ had been mugged or robbed. ${ }^{10}$ Moreover, $58 \%$ of another sample of adolescents from 18 high schools in Cape Town reported that they had witnessed violence in the city. ${ }^{8}$ Alarmingly, 52\% of learners from two high schools in the Northwest Province reported witnessing a rape within their community, while $56.6 \%$ had witnessed a murder. ${ }^{11}$

Considering these statistics, it is imperative to determine the psychological sequelae experienced by South African children exposed to such high degrees of violence. Although research in the area of community violence is, relatively speaking, still in its infancy, it is disconcerting that basic data are lacking in respect of many aspects of children's mental health in South Africa. Additionally, relatively little crosscultural research has been done concerning the epidemiology of mental disorders in different ethnic groups, in particular the black ethnic groups in South Africa. One particular area that has largely remained unexplored is the examination of the psychological effects of exposure to violence amongst South African adolescents. Specifically as exposure to violence has been shown in many studies to be correlated with psychological distress ${ }^{12,13,14}$, most notably depression. ${ }^{15,16,17}$ A range of factors have been identified as potential mediators or moderators of the impact of violence.

Concerning being a victim of violence versus a witness to violence conflicting results between studies have been found. Certain studies have found that witnessing violence may be as traumatic as direct victimization. ${ }^{18,19,20}$ On the other hand, it has been found that victims of violence reported more depressive symptoms after exposure to violence than witnesses, for whom no positive correlation was found between depression and the witnessing of violence. ${ }^{21}$ In terms of the additive effect of violent events, individuals who are both witnesses and victims of violence have been found to express greater distress reactions than individuals who are only victims. For example, a study compared abused children who were also witnesses to interpersonal violence within their homes with adolescents who were victims of abuse, but who were not witnesses to domestic violence. Those who were both victims and witnesses of domestic violence were at a significantly higher risk of developing depression, separation anxiety, PTSD, and oppositional defiant behaviour. ${ }^{22}$

Familial factors can influence whether a child develops depression after being exposed to a violent event. Higher maternal education has been correlated with lower levels of exposure to violence, internalising symptoms, and intrusive thinking among children. ${ }^{23}$ Young children living without their mothers in their homes report more depressive symptoms after exposure to violence than children living with their mothers. ${ }^{21}$ In a study by Fitzpatrick et al. ${ }^{24}$ it was found that familial and personal protective factors acted as a buffer against symptoms of depression. However, exposure to community violence still significantly predicted symptoms of depression. Overstreet et al. ${ }^{17}$ found that, in comparison with smaller families, a large family size was correlated with fewer depressive symptoms, after exposure to violence. GormanSmith and Tolan ${ }^{25}$ found that low family cohesion was related to an increase in depressive symptoms among youth exposed to violence. In a study by Martinez and Richters ${ }^{26}$, it was found that youth who were victims or witnesses of violent events involving family members and those familiar to them were more inclined to report symptoms of distress and depression than incidents in the case of involving strangers. Additionally, youth who were exposed to violence within their homes experienced a greater degree of distress after exposure to violence than those from nonviolent homes.

Gender differences appear to exist concerning not only one's chances of being exposed to violence, but also the likelihood of developing psychological distress after exposure. Boys tend to be exposed to higher overall levels of violence compared to girls, although they experience lower levels of depressive symptoms. 10,20,27 The explanation for the latter tendency probably lies in different coping styles and mechanisms. Govender and Killian ${ }^{12}$ found that boys used a more problem-focused coping style that helped to buffer them from the negative effects of stress. Girls, on the other hand, were prone to a more emotionfocused coping style that was not only less effective, but also seemed to fuel the emotional part of trauma.

Ethnicity may lead to different outcomes following exposure to violence, specifically regarding post exposure depression. ${ }^{28,29}$ However, these differences might simply reflect different levels of exposure to violence and other stress variables, rather than to actual ethnic vulnerabilities e.g. ethnic minority males in the US have been associated with higher levels of exposure to violence than various other ethnic groups. ${ }^{27,30}$ Therefore it seems that they would be at a higher risk of developing depression since the two variables have been significantly correlated. However, not all research corroborates the existence of ethnic differences in respect of prevalence of depression in relation to exposure to violence. ${ }^{20,31,32,33}$ Owing to the possible contaminating influence of unknown variables, as well as the fact that relatively little research has been undertaken in this field, it is difficult to ascertain whether ethnicity plays a significant role as a risk factor in relation to the development of depression.

It seems that if an individual's base level of stress is already high, this can increase a youth's vulnerability to psychological distress after exposure to trauma. ${ }^{5}$ Furthermore, as the number of adverse childhood experiences increases, the likelihood of an individual developing depression in adulthood also increases. ${ }^{34}$

In view of the paucity of cross-cultural research concerning the epidemiology of mental disorders in the black ethnic groups in South Africa ${ }^{35}$, as well as the psychological effect of exposure to violence on South African adolescents, the present study was conducted. The intention was to not only determine the prevalence of depression among Venda and Northern Sotho adolescents, but also to ascertain whether there is a correlation between experiences of violence and the development of depression in these groups. In the process gender differences were also investigated.

\section{Method \\ Sample}

A total of 186 Venda and 151 Northern Sotho adolescents participated in the study. They were all learners from two high schools of the Soutpansberg district in the Limpopo Province. The age of the students, who were in Grades 9 to 
12, ranged from 15 to 18. As far as gender is concerned, 92 Venda and 78 Northern Sotho girls, and 94 Venda and 73 Northern Sotho boys participated. The reason for including these two cultural groups was twofold. Firstly, almost no research data in this field exists on Venda and Northern Sotho adolescents. Secondly, one of the researchers (Bach) lived in that area for a while, with the result that the participants were readily available.

\section{Instruments.}

To achieve the mentioned aims of this study, the following instruments were used:

- Children's Depression Inventory (CDI). ${ }^{36}$ Specifically created for use with children and adolescents, the CDI consists of 27 items that are each rated on a three-point scale. The possible raw score ranges between 0 and 54 . The inventory is indicative of depressive symptoms and includes five subscales concerning negative mood, interpersonal problems, feelings of ineffectiveness, anhedonia and negative self-esteem. As the CDI was developed for a first-grade reading level, it was expected that the participants would not experience any difficulty in reading and interpreting the items. Research in the USA, several studies in South Africa and other countries such as Kenya and Kuwait has shown the CDI to be acceptable in respect of its reliability and validity. ${ }^{21,23,37-39}$ On this basis the psychometric properties of the CDI were viewed to be acceptable.

- Child's Exposure to Violence Form (CEVF. ${ }^{40}$ Exposure to violence was assessed using a somewhat altered version of the CEVF. The form was modified so that the questions were separated into two categories of witnessed and victimization events. This distinction was made because the persons who had been directly exposed to violence may have been more susceptible to depression than those who had only witnessed it. ${ }^{41}$ Two questions on the nature of sexual acts were eliminated and replaced with two new questions, bringing the total number of items to the original 34. The additional items concerned whether the individual had participated in or seen a riot in his or her community. (Incidents of rioting had recently occurred in the rural region where the study took place.) This topic is not covered by the CEVF. The indications are that the questionnaire has adequate psychometric properties. ${ }^{42,43}$

For further analysis the questions on violent incidents were grouped into two categories, namely witnessed events and events of victimisation. However, not all of the 34 items were included into this categorisation, owing to the fact that some of them did not fit into the defined topics. In the statistical analysis, correlation coefficients were calculated between each category and the CDI scores.

The two questionnaires administered were published in English. The principals of both schools reassured the researchers that the participants were capable of understanding written English.

\section{Procedure}

Permission to conduct the study was received from the Department of Education. The two schools were selected on the basis of their large size and their ethnicities (language groups). One of the chosen schools was composed primarily of Venda learners and the other school was comprised mainly of Northern Sotho learners.

\section{Statistical analysis}

To measure the participants' levels of depression, the following five subscales of the CDI were used: Subscale A: negative mood; Subscale B: interpersonal problems; Subscale C: ineffectiveness; Subscale D: anhedonia and Subscale E: negative self-esteem. These five subscales together give a total score of 54. Regarding the exposure to violence a total score was used. For the purposes of all analyses, only raw scores were used.

In keeping with the goals of this study, the first aspect to be investigated was whether the two language groups differed regarding the various depression subscales. For this purpose, the Hotelling $\mathrm{T}^{2}$-test was used.

To determine the second aspect, namely whether there was indeed a positive relationship between the participants' levels of depression and their exposure to violence, the Pearson product-moment correlation coefficient ( $r$ ) was computed with the SAS software programme. ${ }^{44}$

The third aspect of this study was to determine whether the relationships between the two mentioned variables differed for the two language groups. This was achieved by computing the Fisher's r-to-z transformation. The original correlation coefficients are thus transformed according to Fisher's r-to-z transformation before the test statistic value can be computed.

In order to be able to comment on the practical importance of statistically significant results which may have been obtained in this study, the practical significance of the results were also investigated. As a guideline to practical significance, effect sizes were computed. In the computation of the practical significance of the Hotelling $\mathrm{T}^{2}$-value, the mean vectors were compared, and the effect size (f) was computed as follows ${ }^{45}: f=\mathrm{T} / \sqrt{ } \mathrm{N}$.

In order to interpret these effect sizes, the following guidelines were used: $0.1=$ small effect; $0.25=$ medium effect; 0.4 = large effect.

If a statistically significant $\mathrm{T}^{2}$-value was obtained which also had a considerable practical significance, the analysis would need to be followed up with post hoc t-tests. The adjusted effect sizes of these tests would then be determined as follows:

$\delta_{a}=\mu_{1}-\mu_{2} / \sqrt{ } p \sigma^{2}{ }_{1}+q \sigma^{2}{ }_{2}$, where $p$ and $q$ indicate the proportion of participants from the two respective populations. The guidelines for interpretation used here were as follows: $|\delta|=0.2$ : small effect; $|\delta|=0.5$ : medium effect; $|\delta|=0.8$ : large effect (the absolute value of $\delta$ is given, as negative values can be obtained when $\mu_{1}<\mu_{2}$ ).

Investigation was also done as to the linear relationship between the mentioned variables, and in this instance Cohen ${ }^{45}$ suggests that the correlation coefficient, viz. p, be used as effect size. The suggested guidelines for this are as follows:

$\mathrm{p}=0.1:$ small effect; $\mathrm{p}=0.3$ : medium effect; $\mathrm{p}=0.5$ : large effect.

Only in instances where statistically significant results (on the 1 per cent or 5 per cent\% level of significance) were found, were the corresponding effect sizes computed. 


\section{Results}

Tables Ia and Ib, show the distribution of exposure of the Venda and Northern Sotho adolescents to different types of violent events, as well as the distribution of exposure between boys and girls.
According to the preceding table, both language groups are exposed to incredibly high rates of violence.

The types and number of violent events that the participants in the study were exposed to are disconcerting. An especially alarming finding is that the majority of the total

\begin{tabular}{|c|c|c|c|c|c|c|c|c|c|c|c|c|}
\hline \multirow{3}{*}{$\begin{array}{l}\text { Witness to at least } \\
\text { one act of violence }\end{array}$} & \multicolumn{4}{|c|}{ Northern Sotho } & \multicolumn{4}{|c|}{ Venda } & \multicolumn{4}{|c|}{ Total } \\
\hline & \multicolumn{2}{|c|}{ Girls } & \multicolumn{2}{|c|}{ Boys } & \multicolumn{2}{|c|}{ Girls } & \multicolumn{2}{|c|}{ Boys } & \multicolumn{2}{|l|}{ Girls } & \multicolumn{2}{|l|}{ Boys } \\
\hline & $N$ & $\%$ & $N$ & $\%$ & $N$ & $\%$ & $N$ & $\%$ & $N$ & $\%$ & $N$ & $\%$ \\
\hline $\begin{array}{l}\text { Yes } \\
\text { No } \\
\text { Column total }\end{array}$ & $\begin{array}{l}68 \\
10 \\
78\end{array}$ & $\begin{array}{l}87,2 \\
12,8 \\
100,0\end{array}$ & $\begin{array}{l}68 \\
5 \\
73\end{array}$ & $\begin{array}{l}93,2 \\
6,8 \\
100,0\end{array}$ & $\begin{array}{l}91 \\
1 \\
92\end{array}$ & $\begin{array}{l}98,9 \\
1,1 \\
100,0\end{array}$ & $\begin{array}{l}82 \\
12 \\
94\end{array}$ & $\begin{array}{l}87,2 \\
12,8 \\
100,0\end{array}$ & $\begin{array}{l}159 \\
11 \\
170\end{array}$ & $\begin{array}{l}93,5 \\
6,5 \\
100,0\end{array}$ & $\begin{array}{l}150 \\
17 \\
167\end{array}$ & $\begin{array}{l}89,8 \\
10,2 \\
100,0\end{array}$ \\
\hline \multirow{3}{*}{$\begin{array}{l}\text { Victim of at least } \\
\text { one act of violence }\end{array}$} & \multicolumn{4}{|c|}{ Northern Sotho } & \multicolumn{4}{|c|}{ Venda } & \multicolumn{4}{|c|}{ Total } \\
\hline & \multicolumn{2}{|c|}{ Girls } & \multicolumn{2}{|c|}{ Boys } & \multicolumn{2}{|c|}{ Girls } & \multicolumn{2}{|c|}{ Boys } & \multicolumn{2}{|l|}{ Girls } & \multicolumn{2}{|l|}{ Boys } \\
\hline & $N$ & $\%$ & $N$ & $\%$ & $N$ & $\%$ & N & $\%$ & $N$ & $\%$ & N & $\%$ \\
\hline $\begin{array}{l}\text { Yes } \\
\text { No } \\
\text { Column total }\end{array}$ & $\begin{array}{l}45 \\
33 \\
78\end{array}$ & $\begin{array}{l}57,7 \\
42,3 \\
100,0\end{array}$ & $\begin{array}{l}48 \\
25 \\
73\end{array}$ & $\begin{array}{l}65,8 \\
34,2 \\
100,0\end{array}$ & $\begin{array}{l}71 \\
21 \\
92\end{array}$ & $\begin{array}{l}77,2 \\
22,8 \\
100,0\end{array}$ & $\begin{array}{l}73 \\
21 \\
94\end{array}$ & $\begin{array}{l}77,7 \\
22,3 \\
100,0\end{array}$ & \begin{tabular}{|l}
116 \\
54 \\
170
\end{tabular} & $\begin{array}{l}68,2 \\
31,8 \\
100,0\end{array}$ & $\begin{array}{l}121 \\
46 \\
167\end{array}$ & $\begin{array}{l}72,5 \\
27,5 \\
100,0\end{array}$ \\
\hline \multirow{3}{*}{$\begin{array}{l}\text { Exposed to at least } \\
\text { one act of violence }\end{array}$} & \multicolumn{4}{|c|}{ Northern Sotho } & \multicolumn{4}{|c|}{ Venda } & \multicolumn{4}{|l|}{ Total } \\
\hline & \multicolumn{2}{|c|}{ Girls } & \multicolumn{2}{|c|}{ Boys } & \multicolumn{2}{|c|}{ Girls } & \multicolumn{2}{|c|}{ Boys } & \multicolumn{2}{|l|}{ Girls } & \multicolumn{2}{|l|}{ Boys } \\
\hline & $N$ & $\%$ & $N$ & $\%$ & $N$ & $\%$ & $N$ & $\%$ & $N$ & $\%$ & $N$ & $\%$ \\
\hline $\begin{array}{l}\text { Yes } \\
\text { No } \\
\text { Column total }\end{array}$ & $\begin{array}{l}72 \\
6 \\
78\end{array}$ & $\begin{array}{l}92,3 \\
7,7 \\
100,0\end{array}$ & $\begin{array}{l}68 \\
5 \\
73\end{array}$ & $\begin{array}{l}93,2 \\
6,8 \\
100,0\end{array}$ & $\begin{array}{l}92 \\
0 \\
92\end{array}$ & $\begin{array}{l}100,0 \\
0,0 \\
100,0\end{array}$ & $\begin{array}{l}88 \\
6 \\
94\end{array}$ & $\begin{array}{l}93,6 \\
6,4 \\
100,0\end{array}$ & \begin{tabular}{|l}
164 \\
6 \\
170
\end{tabular} & $\begin{array}{l}96,5 \\
3,5 \\
100,0\end{array}$ & $\begin{array}{l}156 \\
11 \\
167\end{array}$ & $\begin{array}{l}93,4 \\
6,6 \\
100,0\end{array}$ \\
\hline
\end{tabular}

Table lb: Exposure to violence: language and gender

\begin{tabular}{|c|c|c|c|c|c|c|c|c|c|c|c|c|}
\hline \multirow[t]{2}{*}{ Exposure to violence } & \multicolumn{2}{|c|}{ N. Sotho total } & \multicolumn{2}{|c|}{ N. Sotho girls } & \multicolumn{2}{|c|}{ N. Sotho boys } & \multicolumn{2}{|c|}{ Venda total } & \multicolumn{2}{|c|}{ Venda girls } & \multicolumn{2}{|c|}{ Venda boys } \\
\hline & Yes & No & Yes & No & Yes & No & Yes & No & Yes & No & Yes & No \\
\hline \multicolumn{13}{|l|}{ Witnessed } \\
\hline Beating & 57,1 & 42,9 & 53,1 & 46,9 & 61,3 & 38,7 & 78,6 & 21,4 & 78,9 & 21,1 & 78,4 & 21,6 \\
\hline Stabbing & 36,9 & 63,1 & 36,7 & 63,3 & 37,3 & 62,7 & 49,6 & 50,4 & 58,0 & 42,0 & 41,7 & 58,3 \\
\hline Shooting & 54,6 & 45,4 & 44,3 & 55,7 & 65,5 & 34,5 & 39,5 & 60,5 & 38,9 & 61,1 & 40,0 & 60,0 \\
\hline Home violence & 42,4 & 57,6 & 46,9 & 53,1 & 37,7 & 62,3 & 47,3 & 52,7 & 52,8 & 47,2 & 41,9 & 58,1 \\
\hline Dead body & 25,8 & 74,2 & 21,3 & 78,7 & 30,5 & 69,5 & 37,1 & 62,9 & 34,3 & 65,7 & 40,0 & 60,0 \\
\hline Gun pulled & 39,5 & 60,5 & 37,5 & 62,5 & 41,7 & 58,3 & 33,3 & 66,7 & 21,7 & 78,3 & 44,0 & 56,0 \\
\hline Homeshooting/stabbing & 30,9 & 69,1 & 30,0 & 70,0 & 31,7 & 68,3 & 25,0 & 75,0 & 23,0 & 77,0 & 27,0 & 73,0 \\
\hline Knife pulled & 59,7 & 40,3 & 63,1 & 36,9 & 56,2 & 43,8 & 54,4 & 45,6 & 56,9 & 43,1 & 52,0 & 48,0 \\
\hline Murder & 43,1 & 56,9 & 38,7 & 61,3 & 47,5 & 52,5 & 35,2 & 64,8 & 31,2 & 68,8 & 39,7 & 60,3 \\
\hline Suicide & 44,4 & 55,6 & 41,2 & 58,8 & 48,2 & 51,8 & 44,9 & 55,1 & 51,4 & 48,6 & 38,4 & 61,6 \\
\hline Sexual assault & 39,4 & 60,6 & 36,4 & 63,6 & 42,6 & 57,4 & 39,9 & 60,1 & 43,9 & 56,1 & 36,1 & 63,9 \\
\hline Riot & 39,5 & 60,5 & 37,1 & 62,9 & 42,1 & 57,9 & 37,9 & 62,1 & 39,1 & 60,9 & 36,6 & 63,4 \\
\hline \multicolumn{13}{|l|}{ Victimization } \\
\hline Robbed & 29,7 & 70,3 & 26,7 & 73,3 & 32,8 & 67,2 & 27,6 & 72,4 & 29,7 & 70,3 & 25,4 & 74,6 \\
\hline Beaten up (threat) & 41,1 & 58,9 & 43,3 & 56,7 & 38,7 & 61,3 & 60,8 & 39,2 & 60,8 & 39,2 & 60,8 & 39,2 \\
\hline Beaten up & 38,4 & 61,6 & 33,3 & 66,7 & 43,5 & 56,5 & 55,1 & 44,9 & 53,6 & 46,4 & 56,4 & 43,6 \\
\hline Threatenedwith murder & 24,8 & 75,2 & 18,5 & 81,5 & 31,3 & 68,7 & 29,7 & 70,3 & 28,6 & 71,4 & 31,0 & 69,0 \\
\hline
\end{tabular}

Note: Majority in bold 
sample had witnessed violent events such as someone being beaten up or an individual pulling a knife on another person. Concerning subgroups, the majority of Venda girls had seen a stabbing, most of the Northern Sotho adolescents had witnessed a person being shot and 51 per cent of the Venda girls had witnessed someone kill themselves or attempt to kill themselves. Another notable finding relates to victimisation: a relatively high number (55 per cent) of the Venda group had been beaten up.

The average scores concerning witnessed violent events, direct victimisation and total exposure to violence were also calculated by means of the t-test for two independent groups. The results appear in Tables II, III,IV.

From Table II it is clear that there is a significant difference (at the 1 per cent level) between the average victimisation scores of the two ethnic groups. The effect size of -0.30 indicates that the difference is of a practical value. It is therefore evident that Venda adolescents were victims of violence to a higher degree than the Northern Sotho adolescents. However, there were no significant differences in the scores for witnessed violence, or the total scores of the two groups. Overall, the two ethnic groups in the present sample were exposed to the same degree of violence, which is consistent with the findings of some international studies. ${ }^{20,46}$

No significant differences occurred in the average scores for witnessed violence, or the victimisation or total scores of the Northern Sotho girls and boys. This finding is consistent with those of the already mentioned South African study and studies in the USA. 8,42,47

Similar to the results for the Northern Sotho adolescents, there were no significant differences between the Venda boys and girls concerning their average scores for witnessed violence or their victimisation or total scores.
In order to calculate the clinical significance for depression, different raw score cut points are applicable to the girls and the boys. For girls, the total raw score threshold on the CDI is 19, and for boys 24. These values are then translated into T-scores. Although a low score, approximately three times as many girls suffer from depression, in comparison to boys. With regard to the prevalence of depression as established in other studies, it has commonly been found that girls experience notably higher rates of depression than boys. ${ }^{10,20}$ In fact, it has even been found in the USA that girls outnumber boys 2:1 in respect of depression. ${ }^{48}$ This finding is quite similar to the results of the present study. However, in this case, there is an even larger gap between the gender groups. As discussed earlier in the literature review, these gender differences in respect of the prevalence of depression could be ascribed to different coping styles; but further exploration of the topic is required. ${ }^{12}$

The following table provides an overall summary of the prevalence of depression, differentiated in terms of gender and ethnicity.

As displayed in Table III the prevalence of depression among Northern Sotho and Venda girls is very similar. However, nearly twice as many Northern Sotho boys are suffering from depression in comparison to the Venda boys. As discussed previously in the literature review, differences in prevalence have been found for psychological distress between ethnic groups within the same country. $28,49,50$

In order to achieve the first goal of the study, the vector means of the depression scores (subscales and total scores) for the two language groups and the two genders in each of the two language groups were compared in the tables below (Table IV and V). To evaluate this comparison, the Hotelling $\mathrm{T}^{2}$-test was used and the evaluation was carried out by means of the BMDP P3D programme. ${ }^{54}$

Table II: Means and standard deviations of the two ethnic groups

\begin{tabular}{|c|c|c|c|c|c|c|c|}
\hline \multirow[t]{2}{*}{ Exposure to violence } & \multicolumn{2}{|c|}{ Northern Sotho (151) } & \multicolumn{2}{|c|}{ Venda $(n=186)$} & \multirow[t]{2}{*}{$t$} & \multirow[t]{2}{*}{$p$} & \multirow[t]{2}{*}{$D$} \\
\hline & $x$ & $s$ & $x$ & $S$ & & & \\
\hline $\begin{array}{l}\text { Witnessed } \\
\text { Victimization } \\
\text { Total }\end{array}$ & $\begin{array}{l}6,91 \\
1,75 \\
18,42\end{array}$ & $\begin{array}{l}5,05 \\
1,97 \\
12,22\end{array}$ & $\begin{array}{l}6,71 \\
2,39 \\
18,43\end{array}$ & $\begin{array}{l}4,88 \\
2,18 \\
11,37\end{array}$ & $\begin{array}{l}0,364 \\
-2,784 \\
-0,005\end{array}$ & $\begin{array}{l}0,7161 \\
0,0057^{*} \\
0,9961\end{array}$ & $-0,30$ \\
\hline
\end{tabular}

\section{Table III: Presence of depression according to ethnic group and gender}

\begin{tabular}{|c|c|c|c|c|c|c|c|c|}
\hline \multirow{3}{*}{ Presence of depression } & \multicolumn{4}{|c|}{ Northern Sotho } & \multicolumn{4}{|c|}{ Venda } \\
\hline & \multicolumn{2}{|c|}{ Girls } & \multicolumn{2}{|c|}{ Boys } & \multicolumn{2}{|c|}{ Girls } & \multicolumn{2}{|c|}{ Boys } \\
\hline & $N$ & $\%$ & $N$ & $\%$ & $N$ & & N & $\%$ \\
\hline Yes & 20 & 28,6 & 8 & 12,1 & 27 & 29,7 & 6 & 6,7 \\
\hline No & 50 & 71,4 & 58 & 87,9 & 64 & 70,3 & 83 & 93,3 \\
\hline Total & 70 & 100,0 & 66 & 100,0 & 91 & 100,0 & 89 & 100,0 \\
\hline
\end{tabular}


A T $^{2}$-value of 8.83 was computed for the information in Table IV, leading to an estimated F-value of 1.45 for 6 and 330 degrees of freedom. However, this value was not significant on at least the 5 per cent significance level $(p=0.1948)$.

A T $^{2}$-value of 3.87 was computed for the Northern Sotho group, leading to an F-value of 0.62 for 6 and 144 degrees of freedom. However, this value was not significant on at least the 5 per cent significance level $(p=0.7110)$. Consequently, the deduction could be made that there are no significant differences between the mean depression scores for Northern Sotho boys and girls.

A T $^{2}$-value of 4.86 was computed for the Venda group, leading to an estimated F-value of 0.79 for 6 and 179 degrees of freedom. However, this value was not significant on at least the 5 per cent significance level $(p=0.5802)$. Consequently, the deduction was made that there are no significant differences between the mean depression scores for the Venda boys and girls.

As indicated in the following group of tables, the question of whether a significant positive relationship exists between individuals' depression and their exposure to violence (witnessed, victimisation and total) was investigated. In order to conduct this investigation, Pearson's product moment correlation coefficient was computed. In the first instance, the relationship between these variables was computed for the total group. After this, it was computed separately for the two language groups as well as the two genders in each language group. The results obtained are displayed in Tables VI to IX. Fisher's r-to-z transformation was used to determine where there were differences in this regard between the various language and gender groups.

From Table VI, it is clear that there are significant

\begin{tabular}{|c|c|c|c|c|c|c|}
\hline \multirow[t]{2}{*}{ Depression } & \multicolumn{3}{|c|}{ Northern Sotho } & \multicolumn{3}{|c|}{ Venda } \\
\hline & $N$ & $x$ & s & $N$ & $x$ & $S$ \\
\hline $\begin{array}{l}\text { Depression: Subscale A: Negative Mood } \\
\text { Depression: Subscale B: Interpersonal Problems } \\
\text { Depression: Subscale C: Ineffectiveness } \\
\text { Depression: Subscale D: Anhedonia } \\
\text { Depression: Subscale E: Negative Self-Esteem } \\
\text { Depression: Total score }\end{array}$ & $\begin{array}{l}126 \\
82 \\
118 \\
131 \\
112 \\
136\end{array}$ & $\begin{array}{l}3,82 \\
2,78 \\
2,89 \\
5,48 \\
2,46 \\
15,01\end{array}$ & $\begin{array}{l}2,10 \\
1,49 \\
1,46 \\
2,54 \\
1,43 \\
6,84\end{array}$ & $\begin{array}{l}156 \\
101 \\
150 \\
174 \\
148 \\
180\end{array}$ & $\begin{array}{l}3,76 \\
2,30 \\
2,61 \\
5,48 \\
2,36 \\
13,96\end{array}$ & $\begin{array}{l}2,00 \\
1,57 \\
1,30 \\
2,93 \\
1,25 \\
6,83\end{array}$ \\
\hline
\end{tabular}

Table V: The means and standard deviations of the depression subscales of Northern Sotho and Venda girls and boys

\begin{tabular}{|c|c|c|c|c|c|c|c|c|c|c|c|c|}
\hline \multirow[t]{3}{*}{ Depression } & \multicolumn{6}{|c|}{ Northern Sotho } & \multicolumn{6}{|c|}{ Venda } \\
\hline & \multicolumn{3}{|c|}{ Girls } & \multicolumn{3}{|c|}{ Boys } & \multicolumn{3}{|c|}{ Girls } & \multicolumn{3}{|c|}{ Boys } \\
\hline & $N$ & $x$ & $s$ & $N$ & $x$ & $s$ & N & $x$ & $s$ & $N$ & $x$ & s \\
\hline Depression: Scale A & 63 & 3,71 & 2,20 & 63 & 3,92 & 2,00 & 83 & 3,87 & 2,09 & 73 & 3,63 & 1,90 \\
\hline Depression: Scale B & 48 & 2,88 & 1,49 & 34 & 2,65 & 1,50 & 50 & 2,56 & 1,78 & 51 & 2.04 & 1,30 \\
\hline Depression: Scale C & 58 & 2,88 & 1,58 & 60 & 2,90 & 1,35 & 79 & 2,72 & 1,29 & 71 & 2.48 & 1,31 \\
\hline Depression: Scale D & 68 & 5,69 & 2,63 & 63 & 5,25 & 2,44 & 90 & 5,69 & 2,99 & 84 & 5,26 & 2,87 \\
\hline Depression: Scale E & 61 & 2,57 & 1,24 & 51 & 2,31 & 1,63 & 72 & 2.43 & 1,33 & 76 & 2,29 & 1,17 \\
\hline Depression: Total & 70 & 15,46 & 7,02 & 66 & 14,53 & 6.67 & 91 & 14,85 & 7,20 & 89 & 13,04 & 6,35 \\
\hline
\end{tabular}

Table VI: Correlation coefficients between depression and exposure to violence (witnessed and victimization) for the total group as well as the individual language groups

\begin{tabular}{|c|c|c|c|c|c|c|c|c|}
\hline \multirow[t]{2}{*}{ Depression } & \multicolumn{4}{|l|}{ Witnessed } & \multicolumn{4}{|c|}{ Victimization } \\
\hline & Total group & N. Sotho & Venda & $Z$ & Total & N. Sotho & Venda & $z$ \\
\hline $\begin{array}{l}\text { Depression: Scale A } \\
\text { Depression: Scale B } \\
\text { Depression: Scale C } \\
\text { Depression: Scale D } \\
\text { Depression: Scale E } \\
\text { Depression: Total }\end{array}$ & $\begin{array}{l}0,20^{\star \star} \\
0,33^{\star \star} \\
0,11 \\
0,21^{\star \star} \\
0,08 \\
0,26^{\star \star}\end{array}$ & $\begin{array}{l}0,29^{\star \star} \\
0,48^{\star \star} \\
0,21^{\star} \\
0,29^{\star \star} \\
0,09 \\
0,38^{\star \star}\end{array}$ & $\begin{array}{l}0,11 \\
0,20^{\star} \\
0,02 \\
0,16^{\star} \\
0,07 \\
0,16^{\star}\end{array}$ & $\begin{array}{l}1,60 \\
2,11^{*} \\
1,53 \\
1,17 \\
0,16 \\
2,10^{*}\end{array}$ & $\begin{array}{l}0,08 \\
0,16^{\star} \\
0,04 \\
0,06 \\
0,11 \\
0,14\end{array}$ & $\begin{array}{l}0,10 \\
0,27^{\star} \\
0,10 \\
0,14 \\
0,24^{\star \star} \\
0,24^{\star \star}\end{array}$ & $\begin{array}{l}0,07 \\
0,12 \\
0,01 \\
0,01 \\
0,03 \\
0,09\end{array}$ & $\begin{array}{l}-0,17 \\
-0,76 \\
-0,48 \\
-0,69 \\
-1,07 \\
-0,91\end{array}$ \\
\hline
\end{tabular}


relationships (on the 1 per cent significance level) between three of the five subscales (Scales A, B and D), as well as the total depression scores and the witnessing of violence for the total group. For the Northern Sotho group there were also significant relationships between four of the five depression subscales (Scales A, B, C and D) as well as the total score and the witnessing of violence. On the 5 per cent significance level there were also significant relationships between two of the subscales (Scales B and D), as well as the total depression score and the witnessing of violence for the Venda adolescents.

Furthermore, from Table VI, significant differences (on the 5 per cent level) in the correlations between the two language groups regarding subscale B and the total depression score and the witnessing of violence are indicated. This relationship was often higher for the Northern Sotho than for the Venda speakers

It is also evident that the only significant relationship (on the 5 per cent level) exists on Subscale B between victimization and the total group. For the Northern Sotho group, Subscale B, Subscale E, as well as the total depression score displayed significant relationships with victimisation. No significant relationships between the victimisation and depression scores were found for the Venda group.

As discussed earlier international studies have found that victimisation and witnessed violence can have a differential effect on the corresponding distress experienced for those exposed. In the case of the present study, it seems that victimisation has a weaker overall association with depression than witnessed events, for both groups.

No significant differences between the two language groups were found for the correlations in Table VII. However, significant relationships exist for both the total group (Venda and Northern Sotho) and the Northern Sotho speakers alone, between exposure to violence (total) and all the depression subscales and the total depression score. Furthermore, the significant correlation that was found for the total group was mainly owing to the strong relationships that applied to the Northern Sotho respondents. At the 1 per cent level, for the Venda, there were no significant correlations between these variables. The effect sizes for the statistically significant correlation coefficients were, however, small to medium.

Furthermore, it seems that there were significant differences on the 5 per cent level regarding the correlation of

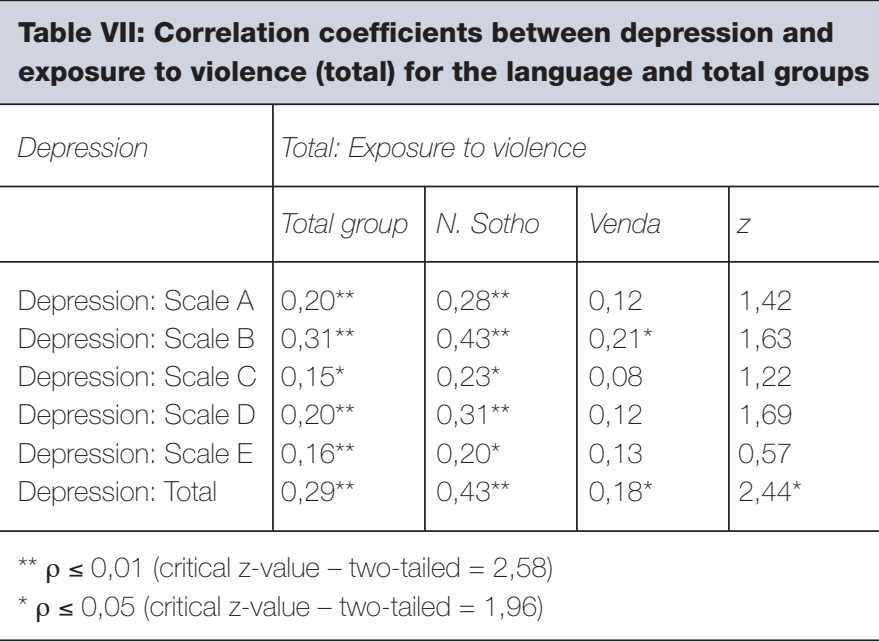

the depression scores and exposure to violence (total score) for the two language groups. The relationship was higher for the Northern Sotho than for the Venda-speaking respondents.

To summarise, Subscale A (negative mood), Subscale B (interpersonal problems), Subscale C (ineffectiveness), Subscale D (anhedonia) and Subscale E (negative selfesteem) and the total score on the CDI were all significantly correlated with the total exposure to violence for the Northern Sotho participants and the total sample, but no significant correlations with these variables were found for the Venda in particular. This suggests that despite the two groups being exposed to similar overall levels of violence and despite there being no significant overall differences between the two groups in respect of the prevalence of depression, the strengths of the correlations between the two variables of total violence and depression are different for the groups.

The same correlation analysis as the one used above is shown in the following tables for the boys and girls in the separate language groups. Also included are the witnessed and victimisation variables. The results of the Northern Sotho and Venda respondents are displayed in Tables VIII and IX respectively.

For the Northern Sotho girls, there is a significant relationship (on the 1 per cent level) between the witnessing of violence, victimisation and the total exposure to violence and the total depression scores, as well as the Subscale B score. In addition, significant relationships were found

Table VIII: Correlation coefficients between depression and exposure to violence (witnessed, victimization and total) for the Northern Sotho boys and girls

\begin{tabular}{|c|c|c|c|c|c|c|c|c|c|}
\hline \multirow[t]{2}{*}{ Depression } & \multicolumn{3}{|c|}{ Witnessed } & \multicolumn{3}{|c|}{ Victimization } & \multicolumn{3}{|l|}{ Total } \\
\hline & Girls & Boys & $z$ & Girls & Boys & $z$ & Girls & Boys & $z$ \\
\hline Depression: Scale A & $0,39^{\star *}$ & 0,18 & 1,25 & 0,19 & $-0,01$ & 1,10 & $0,39^{* \star}$ & 0,14 & 1,47 \\
\hline Depression: Scale B & $0,37^{\star *}$ & $0,65^{\star \star}$ & $-1,67$ & $0,30^{*}$ & 0,27 & 0,14 & $0,39^{* *}$ & $0,56^{\star *}$ & $-0,95$ \\
\hline Depression: Scale C & 0,22 & 0,20 & 0,11 & 0,19 & $-0,01$ & 1,10 & $0,28^{\star}$ & 0,17 & 0,62 \\
\hline Depression: Scale D & $0,27^{\star}$ & $0,33^{\star \star}$ & $-0,37$ & 0,23 & 0,03 & 1,14 & $0,35^{\star *}$ & $0,30^{*}$ & 0,31 \\
\hline Depression: Scale E & 0,01 & 0,16 & $-0,77$ & 0,20 & $0,30^{*}$ & $-0,55$ & 0,16 & 0,26 & $-0,54$ \\
\hline Depression: Total & $0,44^{\star \star}$ & $0,36^{\star \star}$ & 0,54 & $0,35^{\star \star}$ & 0,13 & 1,33 & $0,51^{\star \star}$ & $0,36^{\star \star}$ & 1,06 \\
\hline
\end{tabular}

${ }^{* *} \rho \leq 0,01$ (critical $z$-value - two-tailed $=2,58$ )

$\rho \leq 0,05$ (critical z-value - two-tailed $=1,96$ ) 
Table IX: Correlation coefficients between depression and exposure to violence (witnessed, victimization and total) for the Venda boys and girls

\begin{tabular}{|l|l|l|l|l|l|l|l|l|l|}
\hline \multicolumn{2}{|l|}{ Depression } & \multicolumn{2}{l|}{ Vitnessed } & \multicolumn{2}{l|}{ Total } \\
\hline & Girls & Boys & $z$ & Girls & Boys & $z$ & Girls & Boys & $z$ \\
\hline Depression: Scale A & 0,13 & 0,12 & 0,06 & 0,03 & 0,13 & $-0,62$ & 0,11 & 0,14 & $-0,19$ \\
Depression: Scale B & 0,13 & $0,33^{*}$ & $-1,03$ & 0,24 & $-0,04$ & 1,39 & 0,23 & 0,23 & 0,00 \\
Depression: Scale C & 0,10 & $-0,02$ & 0,73 & 0,11 & $-0,09$ & 1,22 & 0,22 & $-0,03$ & 1,55 \\
Depression: Scale D & 0,19 & 0,16 & 0,20 & 0,02 & 0,01 & 0,06 & 0,13 & 0,13 & 0,00 \\
Depression: Scale E & 0,14 & 0,04 & 0,60 & 0,20 & $-0,16$ & $2,18^{*}$ & $0,31^{* *}$ & 0,01 & 1,86 \\
Depression: Total & $0,21^{*}$ & 0,16 & 0,34 & 0,15 & 0,05 & 0,66 & $0,26^{*}$ & 0,14 & 0,82 \\
\hline
\end{tabular}

${ }^{* *} \rho \leq 0,01$ (critical $z$-value - two-tailed $=2,58$ )

${ }^{*} \rho \leq 0,05$ (critical $z$-value - two-tailed $\left.=1,96\right)$

between the depression Subscales A and D and the witnessing of violence.

A significant relationship on the 1 per cent level was found for the total depression score and the witnessing of violence and the total exposure to violence for the Northern Sotho boys. There were also significant relationships between depression Subscales B and D and the witnessing of violence for these boys. The relationship between the Subscale E and victimisation was also significant. According to the computed z-value, no significant differences were found between the correlations for the two genders.

The total depression score of the Venda girls showed a significant relationship (on the 1 per cent level) with the witnessing of violence as well as the total exposure to violence. There was also a significant relationship on the 1 per cent level between Subscale E and the total exposure to violence.

For the Venda boys, the only significant relationship on the 1 per cent level was between the total depression score and the total exposure to violence. On the 5 per cent significance level, a significant relationship was found between Subscale B and the witnessing of violence.

Although no significant relationship was found between Subscale E and victimisation for the boys and girls, the computed $z$-value indicated that these two coefficients differed statistically from one another to a significant degree.

\section{Discussion}

Particularly concerning is the overall exposure of the Venda girls, all of whom had been either witnessed or been victims of a violent event. In comparison with other South African averages, the results from this sample are quite similar in respect of their extreme levels. For example, in a study by Ensink et al. ${ }^{9}, 95$ per cent of their Xhosa sample from Khayelitsha had witnessed a violent event, and 56 per cent had been victims of a violent event. These results are very similar to those obtained for the present study's total group, of whom 95 per cent had witnessed a violent event, and 68 per cent had been victims of violence. However, the participants in the present study had experienced a higher degree of victimisation. A combined international and local study revealed comparatively lower levels of witnessed violence than in the case of the present sample. In the combined study, 69 per cent of the Kenyan respondents and 58 per cent of the South African adolescents from the Western Cape had witnessed violence. ${ }^{8}$ When these results are compared to the prevalence of violence in the USA, there seem to be equal levels of exposure to violence. For example, Myers and Sanders Thompson ${ }^{5}$ had a sample in which 91 per cent of the participants had witnessed violence and 85 per cent had been victims of violence. Their rate of victimisation, however, was almost 20 per cent higher than for the present sample.

Percentages of exposure regarding the types of violent events in other South African studies varies across samples, although a common factor is that exposure is high. For example, 62 per cent of the adolescents from the Western Cape had been robbed or mugged ${ }^{10}$ and 61 per cent of the adolescents in Khayelitsha had been exposed to taxi violence either as witnesses or as victims.

In Canada and the United States, the prevalence of depression ranges from 1.2 per cent to 8.8 per cent among adolescents. ${ }^{52}$ In South Africa, the prevalence of depression for adolescents in two studies carried out in the Western Cape was 6 per cent to 7 per cent.9.,53 In Kenya Ndetei et $\mathrm{a}^{54}$ found that It is clear from the results of the present study that the female participants, in particular, experienced a significantly higher degree of depression than has been found in the rest of South Africa. In the two other studies the prevalence of depression for the genders was not differentiated, with the result that it is not possible to directly compare the prevalence of depression among girls between all three studies.

In the comparison with regard to gender, no significant differences were found in terms of overall exposure to violence between males and females. With regard to depression, the total group of girls had a remarkably higher prevalence of depression. Regarding ethnic comparison, no significant differences were found in terms of overall exposure to violence, or for witnessed events. However, as far as victimisation was concerned, the Venda had been victims significantly more often. In terms of depression, Venda and Northern Sotho girls had a similar 
prevalence of depression, but Northern Sotho and Venda boys differed significantly. The correlation between victimisation and total group depression was relatively low for the Northern Sotho group, and non-existent for the Venda group. A significant correlation was found between total exposure to violence and depression for the overall group. This was mostly owing to the strength of the Northern Sotho depression and exposure-to-violence correlations.

A valuable dimension that was included in the study was that the violence exposure events were broken down into two categories, namely witnessed violence and direct victimisation, which were then compared in terms of their relative correlations to depressive symptoms. This provided a more detailed picture of the nature of the predictor variables. In addition, the sample size was reasonably large, which adds to the potential generalisability of the findings for this specific geographic region. Another notable element of the study was that it compared the prevalence of depression between specific language groups, as opposed to using a heterogeneous sample, in which possible differences between groups may be overlooked.

However, the aforementioned does not imply that the findings should not be interpreted with caution:

An important limitation is that measuring instruments which are not standardized for the groups that the participants belong to (Venda and Northern Sotho), were used. This also applies to the fact that some items of the CEVF were also rearranged. This lack of data on the reliability and validity of the instruments could have impacted negatively on the results. A related limitation concerns language. The tests administered for the study were in English, which may not be a language spoken regularly among the Venda and Northern Sotho participants. Despite English being a language of instruction in both schools, it is possible that in certain cases misinterpretation of the questions occurred, owing to the words being misunderstood. It could be hypothesised that if the questionnaires had been translated into the participants' home languages, the results may have provided a more accurate picture. Several authors such as Edwards and Moldan ${ }^{55}$ emphasise that even though participants who have English as their second language are fluent in English, they can stil misunderstand certain items in a questionnaire.

The CDI was developed to assess the depression symptoms of children between the ages of 12 and 17. Due to practical reasons the present sample, however, also included 18-year-old participants. In historically black schools in South Africa, learners of 18 years and even older are often in the same grades as much younger learners.

It is important that the findings regarding the exposure to violence should be interpreted against the fact that only the incidence of violent events was measured - not the degree of intensity of the specific event. Furthermore, the specific area (home, school, community, etc) where the violence occurred, was also not investigated in this study. The hope is expressed that these lacunas will receive the necessary research attention in the future.
The fact that variables such as abuse and parental conflict as contributing factors were excluded as (CO-) causal determinants of the participants' symptoms, must be taken into account when interpreting the results. Another lacuna of this study is its lack of generalisability to Venda and Northern Sotho adolescents from other geographic regions. There are possibly significant differences in the levels of violence experienced between rural regions, such as the one where this study was conducted, and urban areas in South Africa. Previous research has indicated that urban settings often have a greater incidence of violence than sub-urban and rural environments. ${ }^{20}$ Further investigation in this regard is therefore required in South Africa. Additionally, other language groups in South Africa may have different intervening variables from those that are applicable to this Venda and Northern Sotho sample from the Limpopo Province.

It should also be taken into account that the study relies exclusively on self-reported data, which may not be entirely accurate, owing to the presence of a possible selfreport bias. Multiple-measurement for depression would have made the prevalence results more reliable, such as the inclusion of a clinical assessment from a trained clinician to determine the presence of depression.

\section{Conclusion}

In the light of the prevalence of depression in the study, the widespread nature of violence occurring in South Africa, and the correlation between exposure to violence and depression, it is clear why adolescents' exposure to violence and mental health are very serious concerns. It seems that, when conducting future research in this regard, it would be advisable to evaluate other intervening variables that may provide greater insight into the relationship between depression and exposure to violence.

A possible point of departure for intervention in respect of the mental health situation in South Africa would be to find out how to enhance the pre-existing strengths and resources that communities already have, which have contributed to the resilience of certain people in the face of adversity. For example, children could be taught effective coping and problem-solving techniques in schools to help empower them against the stressors surrounding them. Moreover, all levels of society must play an active role in trying to address the current strife going on in South Africa, from the micro- to the macro-level of society. Teachers, parents, health care workers and children need to be educated in how to identify individuals who may be suffering from depression. This would assist in getting proper help to those who need it before depression seriously affects all levels of a child's functioning. Moreover, awareness must be created in respect of how violence can adversely affect those who are exposed to it. Where finances are often lacking and hiring professional mental health care workers is not a viable option, communities need to be encouraged and taught how to create support groups within their neighbourhoods, and especially in their schools, to help support those who are most vulnerable. 


\section{Acknowledgements}

Special thanks to Dr. Beverley Peens and Lyzette Hoffman for their editorial assistance

\section{References}

1. Butcher JN, Mineka S, Hooley JM. Abnormal Psychology. 13th edition. USA: Pearson Education, Inc. 2007.

2. Esterhuyse KGF, Louw DA, Bach JM. Post-traumatic stress disorder and exposure to violence among Venda and Northern Sotho adolescents, Health SA Gesondheid 2007; 12 (2):63-72.

3. Goenjian AK, Steinberg ML, Fairbanks LA, Alverez ML, Goenjian HA, Pynoos RS. Post-traumatic stress and depressive reactions among Nicaraguan adolescents after Hurricane Mitch. Am J Psychiatry 2001; 158:788-794.

4. Louw DA, Duncan $N$, Richter L, Louw AE. Vulnerabilities, resilience and rights of children. In DA Louw, AE Louw (Eds). Child and adolescent development. Bloemfontein: Psychology Books. 2007

5. Myers MA, Sanders Thompson VL. The impact of violence exposure on African American youth in context. Youth Soc 2000; 32(2):253-267.

6. Aisenberg E, Ayon C, Orozco-Figueroa A. The role of young adolesncets' perception in understanding the severity of exposure to community violence and PTSD. J Interpers Violence, 2008; 23:1555-1578.

7. Department of Community Services. Domestic violence and its impact on children's development. 2002. Retrieved from http://wWw.community.n.sw.gov.au/documents/dv_paper.pdf, March 29, 2005.

8. Seedat S, Nyamai C, Njenga F, Vythilingum B, Stein DJ. Trauma exposure and posttraumatic stress symptoms in adolescents: $A$ schools survey in Cape Town and Nairobi. Br J Psychiatry, 2004; 184:169-175.

9. Ensink K, Robertson AB, Zissis C, Leger P. Post-traumatic stress disorder in children exposed to violence. S Afr Med J, 1997; 11:1526-1530.

10. Seedat $S$, van Nood E, Vythilingum B, Stein DJ, Kaminer D. School survey of exposure to violence and posttraumatic stress symptoms in adolescents. S Afr J Child Adoles Ment Health, 2000; 12:38-44.

11. Muller Y. Adolescents' experience of violent episodes. Unpublished master's thesis, Department of Psychology, University of Potchefstroom, Potchefstroom. 2001.

12. Govender K, Killian BJ. The Psychological effects of chronic violence on children living in South African township.s. S Afr J Psychol, 2001; 31:1-11.

13. Margolin G, Gordis EB. Children's exposure to violence in the family and community. Curr Direct Psychol Sci 2004; 13(4):152155.

14. Zissis C, Ensink K, Robertson B. A community study of taxi violence and distress symptoms among youth. S Afri J Child Adoles Ment Health 2000; 12:151-161.

15. Curry A, Latkin C, Davey-Rothwell M. Pathways to depression: The impact of neighbourhood violent crime on inner-city residents in Baltimore, Maryand, USA. Soc Sci Med 2008; 67:2330.

16. Kilpatrick DG, Ruggiero KJ, Acierno R, Saunders BE, Resnick HS, Best CL. Violence and risk of PTSD, major depression, substance abuse/dependence, and comorbidity: Results from the national survey of adolescents. J Consul Clin Psychol 2003;
$71(4): 692-700$.

17. Overstreet S, Dempsey M, Graham D, Moely B. Availability of family support as a moderator of exposure to community violence. J Clin Psychol, 1999; 28(2):151-159.

18. Fitzpatrick KM, Boldizer JP. The prevalence and consequences of exposure to violence among African-American Youth. J Am Aca Child Adolesc Psychiatry 1992; 32 (2):424-430.

19. Jaffe P, Wolfe D, Wilson S, Zak L. Similarities in behavioural and social maladjustment among child victims and witnesses to family violence. Am J Orthopsychiatry, 1986; 56:142-146.

20. Singer MI, Anglin TM, Song LY, Lunghofer L. Adolescents' exposure to violence and associated symptoms of psychological trauma. JAMA, 1995; 273:477-482.

21. Fitzpatrick KM. Exposure to violence and prevalence of Depression among low-income African-American youth. J Consult Clin Psychol 1993; 61:528-531.

22. Pelcovitz D, Kaplan SJ, DeRosa RR, Mandel FS, Salzinger S. Psychiatric disorders in adolescents exposed to domestic violence and physical abuse. Am J Orthopsychiatry 2000; 70:360-368.

23. Kliewer W, Oskin D, Johnson P, Lepore S. The Role of Social and Cognitive Processes in Children's Adjustment to Community Violence. J Consult Clin Psychol 1998; 66(1): 199-209.

24. Fitzpatrick KM, Piko BF, Wright DR, LaGory M. Depressive symptomotology, exposure to violence, and the role of social capital among African American adolescents. Am J Orthopscyhiatry 2005; 72:262-274.

25. Gorman-Smith $D$, Tolan $P$ The role of exposure to community violence and developmental problems among inner-city youth. Dev Psychopathol 1998; 10:101-116.

26. Martinez P, Richters JE. The NIMH Community Violence Project: II. Children's distress symptoms associated with violence exposure. Psychiatry 1993; 56:22-35.

27. Berton MW, Stabb SD. Exposure to violence and post-traumatic stress disorder in urban adolescents. Adolesc 1996; 31:489-498.

28. Mghir R, Raskin A. The psychological effects of the war in Afghanistan on young Afghan refugees from different ethnic backgrounds. Int J Soc Psychiatry 1999; 45:29-40.

29. Lei Yu D, Seligman MEP. Preventing Depressive Symptoms in Chinese Children. Prev Treat (5) 2002. Retrieved from http://journals.apa.org/ prevention/volume5/pre0050009a.html on September 22, 2003.

30. National Center for Juvenile Justice. Juvenile offenders and victims: 1999 national report. 1999. Retrieved Mar. 10, 2005, from National Criminal Justice Reference Title Web site: http://www.ncjrs.org/html/ojjdp/nationalreport99/toc.html.

31. Ramos B, Jaccard J, Guilamo-Ramos V. Dual ethnicity and depressive symptoms: Implications of being black and Latino in the United States. Hisp J Behav Sci 2003; 25(2):147-173.

32. Cooley-Quille MR, Turner SM, Beidel DC. Emotional Impact of Children's Exposure to Community Violence: A preliminary Study. J Am Acad Child Adolesc Psychiatry 1995; 34(10):13621368.

33. Schwab-Stone M, Chuansheng C, Greenberger E, Silver D, Lichtman J, Voyce C. No safe haven II. The Effects of Violence Exposure on Urban Youth. J Am Acad Child Adolesc Psychiatry 1999; 38(4):359-367.

34. Anda RF, Whitfield CL, Felitti VJ, Chapman D, Edwards VJ, Dube SR, et al. Adverse Childhood Experiences, Alcoholic Parents, and Later Risk of Alcoholism and Depression. Psychiatr Serv 2002; 53:1001-1009 
35. Mosotho NL, Louw DA, Calitz FJW, Esterhuyse KGF. Depression among Sesotho speakers in Mangaung, South Africa. Afr J Psychiatry 2008; 11:35-43.

36. Kovacs M. Children's Depression Inventory. Toronto: Multihealth systems. 1992.

37 Jansen van Rensburg J. Exposure to violence and the presence of depressive symptomatology among children in the North West Province. (2001). Unpublished Masters' dissertation, Potchefstroom University for Christian Higher Education: Potchefstroom

38. Ndetei DM, Khasakhala L, Seedat S, Syanda J, Ongecha-Owur FA, Kokonya DA, et al. Psychometric properties of a multidemnesional anxiety scale for children (MASC) amongs Nairobi public secondary school children, Kenya. J Child Adol Ment Health 2007; 20(2): 101-109

39. Al-Balhan E. The Children's Depression Inventory as a reliable measure for post-Iraqi invasion Kuwaiti youth. Soc Beh Pers: Int J 2006; 34:351-366

40. Amaya-Jackson L. Child's Exposure to Violence Form. Durham, NC: Center for Child and Family Health, Duke University. 1995.

41. Duckworth MP, Hale DD, Clair SD, Adams HE. Influence of interpersonal violence and community chaos on stress reactions in children. J Interpers Viol 2000; 15(8):806-826.

42. Fehon D, Grilo C, Lipschitz D. Gender differences in violence exposure and violence risk among adolescent inpatients. J Nerv Ment Dis 2001; 189:532 -540.

43. Lipschitz D, Grilo C, Fehon D, McGlashan T, Southwick S. Gender differences in the associations between posttraumatic stress symptoms and problematic substance use in psychiatric inpatient adolescents. J Nerv Ment Dis, 2000; 188:349-356.

44. SAS Institute. SAS user's guide: Statistics version. (5th ed.). Cary, NC: Author. 1985.

45. Steyn HS. Praktiese beduidendheid: Die gebruik van effekgroottes. Potchefstroom : Publikasiebeheerkomitee, $P U$ vir CHO. 1999.
46. Cooley M, Turner SM, Beidel DC. Assessing Community Violence: The Children's Report of Exposure to Violence. J Am Acad Child Adolesc Psychiatry 1995; 34(2):201-208.

47. Mazza JJ, Reynolds WM. Exposure to violence in younger innercity adolescents: Relationships with suicidal ideation, depression, and PTSD symptomatology. J Abnorm Child Psychol 1999; 27:203-213.

48. University of Michigan. Facts about depression in children and adolescents. 2005. Retrieved March 30, 2005 from University of Michigan, Depression Center Website www.med.umich.edu/depression/caph.html.

49. Crouch J, Hanson R, Saunders B, Kilpatrick D, Resnick H. Income, Race/Ethnicity, and exposure to violence in youth: Results from the national survey of adolescents. J Com Psychol 2000; 28:625-641.

50. Perilla J, Norris F, Lavizzo E. Ethnicity, Culture, and Disaster Response: Identifying and explaining ethnic differences in PTSD six months after Hurricane Andrew. J Soc Clin Psychol, 2002; 21:20-45.

51. Dixon WJ. Biomedical computer programs. Berkeley, CA: University of California Press. 1985.

52. Naidoo K. Literature Review for Depression in Adolescents. Alberta Mental Health Board. 2002. Retrieved from http://www.amhb.ab.ca/chmh/resources/page. cfm?pg=Depression on November 24, 2003.

53. Ward C, Flisher A, Zissis C, Muller M, Lombard C. Exposure to violence and its relationship to psychopathology in adolescents. Inj Prev, 2001; 7:297-301.

54. Ndetei DM, Khasakhala L, Nyabola L, Ongecha-Ouor F, Seedat $S$, Mutiso $V$, et al. The prevalence of anxiety and depression symptoms and syndromes in Kenyan children and adolescents. J Child Adolesc Ment Health, 2008; 20(1):33-51.

55. Edwards D, Moldan S. Bulimic pathology in black students in South Africa: Some unexpected findings. South African Journal of Psychology 2004; 34: 191-205 